\title{
Nutrition and health status of health care professionals
}

\begin{abstract}
Health care professionals are having several occupational risks than the rest of the population because of the specificity of their working conditions. Since the health of health care professionals affects their performances, self-care may examine closely to improve the health care system. Therefore, this study was conducted to state nutritional and health status of health care professionals, performing a survey including dietary intake pattern and health status query. This was a cross sectional study carried out among health care professionals who were working at hospitals in Istanbul and Izmir-Turkey. A total of 62 health care professionals were interviewed face to face by using pre-tested questionnaire. Mean age of subjects was $38.66 \pm 10.05$ years. Fifty eight percent $(58.1 \%)$ of health care professionals were female. The mean BMI value was $25.40 \pm 4.32$ and $53.22 \%$ of the health care professionals had a BMI value over 25. Twenty six percent of the subjects were declared to suffer from chronic diseases such as CVD, stomach and gut problems, high cholesterol, hypertension and diabetes. Sixty four percent of the subjects had a family history of diseases. It was observed that more than half of the participants $(59.0 \%)$ were regularly taking three meals a day. Among them, 11.3\% was taking supplement. Mean vegetable and fruit consumptions in portion per day were $1.23 \pm 0.54$, and $1.05 \pm 0.59$, respectively. Water consumption was $1.64 \pm 0.83$ litter/day. The irregular working conditions of health care professionals may affect their nutritional and health status. This pilot study gave an opportunity to analyze the health care professionals' status concluding that nearly half of the population could not take three meal regularly, more than $50 \%$ of subjects had BMI value over 25.0 and $26 \%$ had chronic diseases.
\end{abstract}

Keywords: nutritional status, diet intake pattern, health status, health care professionals
Volume I Issue 6 - 2014

\author{
Nihal Buyukuslu, Yasemen Velioglu, Hilal Hizli \\ Department of Nutrition and Dietetics, Istanbul Medipol \\ University, Turkey
}

Correspondence: Nihal Buyukuslu, Department of Nutrition and Dietetics, School of Health Sciences, Istanbul Medipol University, Beykoz/lstanbul, 348I0, Turkey, Tel +9021668I5300, +902166815380, Fax +902125317555,

Email nbuyukuslu@medipol.edu.tr

Received: October 30, 2014 | Published: December 16, 2014
Abbreviations: BMI, body mass index; CVD, cardiovascular diseases; AHA, American health association

\section{Introduction}

Health care professionals have been reported to have several occupational risks due to the specific working conditions including the health system, work-related factors, financial pressures, lifestyle related factors. ${ }^{1-3}$ Stress, burnout, mental health disorders and substance abuse are the most common studied risks, however daily life styles, nutrition, sleep and self-care are not paid attention effectively. ${ }^{4}$ The health professionals tend to promote preventive health practices to their patients whereas they do not show enough consideration for their own health. ${ }^{5,6}$ They usually think that their health status is better than that of other people who are out of the health care sector. ${ }^{78}$ Therefore they do not tend to use primary health care utilities regularly and do prefer self treatment. ${ }^{9,10}$ There are several studies report that health care professionals in good physically and psychologically conditions show optimal care for patients comparing with the unhealthy associates. ${ }^{11-13}$

An overview of recent Norwegian research into physicians' health problems suggested that physicians' physical health was similar to the general population. ${ }^{9}$ Moreover, studies in Portugal and Israel reported that health care professionals revealed similar healthier behaviors than non-health care professionals did such as avoiding smoking and alcohol consumption and practicing exercise more often. Therefore, the risk to get several diseases for health professionals was found lower than general population..$^{13,14}$ Nonetheless, there are also studies to explore significantly higher risk of mental disorders of health professionals such as depression and tendency to suicide. ${ }^{15,16}$ Depression was also demonstrated to be a factor for myocardial infarction in male physicians. ${ }^{11,17}$ In addition, a comprehensive meta-analysis provided strong evidence for the association between depression and the risk of cardiovascular disease. ${ }^{18}$

Healthy eating is essential to maintain health and to prevent many nutrition based diseases such as cardiovascular disease, stroke, hypertension, and obesity. For a healthy life, the American Health Association (AHA) recommended to aim for a healthy body weight, be physically active and consume a healthy diet with a variety of foods from all the food categories, emphasizes fruits and vegetables and reduce the levels of saturated fat $(<7 \%$ of energy), trans fat $(<1 \%$ of energy), and cholesterol ( $<300 \mathrm{mg} /$ day). ${ }^{19}$ However, it was reported that the high stress of health care professionals in their workplaces resulted in poor eating habits, low level of physical activity, smoking/ alcohol use and weight gain in addition to anxiety and depression. ${ }^{20-22}$

Therefore, the present study was conducted to explore nutritional and health status of health care professionals in Turkey, performing a survey including dietary intake pattern and health status query.

\section{Materials and methods}

This was a cross sectional study carried out among health care professionals between March and April 2014. A total of 62health care professionals working in city hospitals in Istanbul and Izmir (Turkey) 
were interviewed face to face by using pre-tested questionnaire. Among the population, fifty were doctors, seven were dentist, one is nurse and four were other health care professionals. The questionnaire involved demographic and anthropometrical information, health and nutritional status, and physical activities. Nutritional and health information was obtained via face to face interview from the subjects by a trained interviewer through the participants' own declaration. Consumption frequencies of red meat, legumes, soft drinks, sweets, nuts and dry fruits were identified. Survey for food frequency was designed with five answers including "every day", "1-2days", "3-4days", ">4days" and "never taking". The daily vegetable, fruit and water consumptions were calculated as portion per person. The amounts of daily consumption of the food and drink were recorded in grams or milliliters. The BeB is (version 7.2, Pacific Company, Istanbul, Turkey) nutrient analysis program was used to estimate the daily intake of nutrients. The supplement consumption was recorded, and the most consumed supplements were defined. The health status data were obtained by asking health care professionals to assess their own health and also that of the first-degree relatives to get the family history.
The Statistical Package for Social Sciences (SPSS, version 18.0) was used to calculate the means \pm standard deviation and percentages.

\section{Results and discussion}

\section{Demographic and anthropometric parameters of the health care professionals}

From 62 health care professionals, 26were women and 36 were men. The mean age was $38.66 \pm 10.05 y$ years. The distribution of ages were 24-35years (27 person), 36-45years (19 person), and over 46years (16 person). Sixty six percent of the health care professionals were married. The daily working time was $9.24 \pm 2.39$ hours. The average of working time was $10.36 \pm 9.87$ years. They were working $5.96 \pm 0.99$ days in a week. Twenty nine percent of the subjects were smoking cigarette. They have been smoking 13.93 \pm 7.86 years and the average daily consumption was $11.23 \pm 8.85$ cigarette. The BMI value was $25.40 \pm 4.32$. Nearly half of the health care professionals $(53.22 \%)$ had a BMI value over 25.A cross-sectional study in Turkey also indicated $65.50 \%$ of health personnel had normal body weight ${ }^{23}$ (Table 1).

Table I Demographic and anthropometric parameters of the health care professionals $(n=62)$

\begin{tabular}{|c|c|c|}
\hline Parameter & Percentage (\%) & Mean sSD \\
\hline Age (years) & & $38.66 \pm 10.05$ \\
\hline 24-35(years) & 43.5 & \\
\hline $36-45$ (years) & 30.6 & \\
\hline >46(years) & 25.8 & \\
\hline Women & 58.1 & \\
\hline Men & 41.9 & \\
\hline Weight (kg) & & $75.96 \pm 16.19$ \\
\hline Height (cm) & & $172 \pm 9.34$ \\
\hline BMI $\left(\mathrm{kg} / \mathrm{m}^{2}\right)$ & & $25.40 \pm 4.32$ \\
\hline < 8.5 (underweight) & 1.6 & \\
\hline I8.5-24.9 (normal) & 45.2 & \\
\hline$\geq 25.0$ (overweight) & 53.2 & \\
\hline Daily working time (hours) & & $9.24 \pm 2.39$ \\
\hline Total working time (years) & & $10.36 \pm 9.87$ \\
\hline Working days in a week (day) & & $5.96 \pm 0.99$ \\
\hline \multicolumn{3}{|l|}{ Marital status } \\
\hline Married & 66.1 & \\
\hline Unmarried & 33.9 & \\
\hline \multicolumn{3}{|l|}{ Smoking } \\
\hline Yes & 29.0 & \\
\hline Smoking period(years) & & $13.93 \pm 7.86$ \\
\hline Number of cigarettes in a day & & 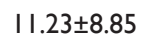 \\
\hline \multicolumn{3}{|l|}{ Alcohol consumption } \\
\hline Yes & 32.3 & \\
\hline
\end{tabular}




\begin{tabular}{|c|c|c|c|}
\hline Parameter & Percentage (\%) & Mean sSD & \\
\hline \multicolumn{4}{|l|}{ Physical activities } \\
\hline & Regular activity (\%) & Daily walking -outside (\%) & Daily walking -in work place (\%) \\
\hline Yes & 44.3 & 75.4 & 46.8 \\
\hline Every day & 3.7 & 26.7 & 35.7 \\
\hline I-2times in a week & 63.0 & 28.9 & 28.6 \\
\hline 3-4times in a week & 29.6 & 37.8 & 32.1 \\
\hline
\end{tabular}

BMI, body mass index

\section{Health status of the health care professionals}

Twenty six percent of the subjects were declared to suffer from chronic diseases which were CVD (1.6\%), stomach (11.3\%) and gut problems $(1.6 \%)$, high cholesterol $(8.1 \%)$, hypertension $(4.8 \%)$, and diabetes $(3.2 \%)$. From the declaration of participants it was defined that $64.5 \%$ of the family members had chronic diseases; among them, $40.3 \%, 46.8 \%, 19.4 \%, 4.8 \%, 22.6 \%$ were diabetes, hypertension, high cholesterol, asthma and CVD respectively. Researchers showed that dietary factors influence the risk of developing diseases and their risk factors. Cardiovascular disease is one of the nutrition related diseases. In addition, healthy dietary patterns are associated with a substantially reduced risk of CVD, diabetes, obesity, and other diseases. ${ }_{24-27}$ The relation between nutritional status and diseases such as obesity and CVD is well-documented. ${ }^{28,29}$ Excess body weight is one of the results of sedentary life style. It was shown that CVD risk factors were associated with increasing blood low-density lipoprotein levels, cholesterol levels, triglyceride levels, blood pressure, and blood glucose levels and decreasing high-density lipoprotein cholesterol levels. As a result, the risk of developing coronary heart disease, heart failure, stroke, and cardiac arrhythmias increased. ${ }^{30-32}$ Both prolonged period of sitting ${ }^{33}$ and of standing ${ }^{34}$ also caused health related risks. In the present study, $44.3 \%$ of attendees informed to have regular physical activity, but only $3.7 \%$ was exercising every day and $63.0 \%$ was 1-2times in a week (Table 2).

Table 2 Health status of the health care professionals $(n=62)$

\begin{tabular}{ll}
\hline Items & $\%$ \\
\hline Chronic diseases & 25.8 \\
Yes & 74.2 \\
No & 1.6 \\
CVD & 11.3 \\
Stomach & 1.6 \\
Gut & 8.1 \\
High cholesterol & 4.8 \\
Hypertension & 3.2 \\
Diabetes & 6.2 \\
Other & \\
Family History & 64.5 \\
Yes & 22.6 \\
CVD & 4.8 \\
Asthma & 19.4 \\
High cholesterol & 46.8 \\
Hypertension & 40.3 \\
Diabetes & 4.2 \\
Other & \\
\hline
\end{tabular}

CVD, cardiovascular diseases 


\section{Nutritional status of the health care professionals}

It was observed that more than half of the health care professionals $(59.0 \%)$ were taking three meals in a day regularly and $27.9 \%$ were taking irregularly. In a similar manner, a study on 400 health personnel in Turkey showed that $62.25 \%$ were taking three meals in a day and breakfast was the most skipping meal. ${ }^{23}$ Eleven percent of the subjects were taking supplement which were fish oil (4.2\%), multivitamin (5.7\%) and protein powder (1.4\%). Mean vegetable and fruit consumptions in portion per day were $1.23 \pm 0.54$, and $1.05 \pm 0.59$, respectively, which is approximately half of the recommended daily intake. Daily water consumption was $1.64 \pm 0.83$ liter. Daily frequency of food intake of participants was red meat $(23.0 \%)$, soft drinks $(13.3 \%)$, nuts and dry fruits $(11.5 \%)$ and sweets(13.1\%). Red meat was consumed $23.0 \%$ in $1-2$ days, $49.2 \%$ in $3-4$ days weekly by participants and $3.3 \%$ never consumed. The frequencies of legumes and the percentages were $1-2$ days $(68.9 \%)$ and 3-4days (16.4\%) in a week. $16.1 \%$ consumed rarely and $1.6 \%$ never consumed. Thirty percent of participants never consumed soft drinks, $13.3 \%$ every day. It is well documented that consumed sugars affects oral health. ${ }^{35}$ Although health professionals are aware of the relation between diet and dental health, $70 \%$ of the participants did not seem to avoid sugar added drinks for protection their oral health. The highest frequency $(47.5 \%)$ for nuts and dry fruits was 1-2days weekly. There was none to declare never consumed nuts and dry fruits. Thirty two percent of the participants consumed sweets 3-4days in a week. Daily intake of nuts and dry fruits can be prompted because of unsaturated fat, minerals and high-quality vegetable protein in their ingredient ${ }^{36}$ (Table 3).

Table 3 Nutritional status of the health care professionals $(n=62)$

\begin{tabular}{|c|c|c|c|c|c|}
\hline Items & $\%$ & \multicolumn{4}{|c|}{ Mean \pm SD } \\
\hline \multicolumn{6}{|l|}{ Taking three meal regularly } \\
\hline Yes & 59.0 & & & & \\
\hline Vegetable consumption (portion/day) & & \multicolumn{4}{|l|}{$1.23 \pm 0.54$} \\
\hline Fruit consumption (portion/day) & & \multicolumn{4}{|l|}{$1.05 \pm 0.59$} \\
\hline Water consumption (liter/day) & & \multicolumn{4}{|l|}{$1.64 \pm 0.83$} \\
\hline \multicolumn{6}{|l|}{ Supplement consumption (\%) } \\
\hline Yes & 11.3 & & & & \\
\hline No & 88.7 & & & & \\
\hline Fish oil supplement & 4,2 & & & & \\
\hline Multivitamin supplement & 5,7 & & & & \\
\hline Protein powder & 1,4 & & & & \\
\hline \multicolumn{6}{|l|}{ Consumption frequencies of food items } \\
\hline Period & Red meat & Legumes & Soft drinks & Nuts and dry fruits & Sweets \\
\hline Every day & 23.0 & 0.0 & 13.3 & 11.5 & 13.1 \\
\hline I-2days & 21.3 & 68.9 & 11.7 & 47.5 & 27.9 \\
\hline 3-4days & 49.2 & 16.4 & 18.3 & 32.8 & 32.8 \\
\hline$>4$ days & 3.3 & 13.1 & 26.7 & 8.2 & 19.7 \\
\hline Never taking & 3.3 & 1.6 & 30.0 & 0.0 & 6.6 \\
\hline
\end{tabular}

\section{Conclusion}

In the present manuscript we focused on the nutritional and health status of health care professionals. We defined that nearly half of the population could not take three meal regularly, more than $50 \%$ of subjects had BMI value over 25.0 and $26 \%$ had chronic diseases. They

were not consuming adequate vegetables, fruits and water. Half of the attendees remained inactive.

To achieve and maintain a healthy body weight it is recommended to balance caloric intake and physical activity. The best way to follow a healthy diet is to consume a balanced diet which is rich in vegetables and fruits, whole-grain, fiber and lean meats and avoid 
beverages and foods with added sugars. The daily intake of saturated fat and cholesterol was recommended to be reduced to $<7 \%$ of energy and $<300 \mathrm{mg}$ /day respectively. ${ }^{21,24,37}$ Despite the high awareness and perceptions of health care professionals in relation to nutrition and health, in our study we defined that they have unbalanced diet in their daily working hours; consuming inadequate vegetables, fruits and water.

Health status of health professionals is one of the major issues all around the world. Traditionally health professionals have a tendency not to care their health and nutrition properly because they believe that they are never ill. There is a certain need for continued promotion of self-care but avoiding self-treatment for health professionals. In last decade, there have been several attempts to provide preventive health care for professionals. ${ }^{38}$ We strongly recommend effective education programs to raise awareness and perceptions of health care professionals about how they are able to manage healthy balanced diet in their daily life and increase physical activity levels.

\section{Acknowledgements}

The authors would like to thank volunteer health professionals who participated in the study.

\section{Conflict of interest}

The author declares no conflict of interest.

\section{References}

1. Shadbolt N. Is being a doctor bad for your health? Radius. 2009;22(1):15-16.

2. Hickam DH, Severance S, Feldstein A, et al. The effect of health care working conditions on patient safety. Evid Rep Technol Assess (Summ). 2003;74:1-3.

3. Rice V, Glass N, Ogle KR, et al. Exploring physical health perceptions, fatigue and stress among health care professionals. J Multidiscip Healthc. 2014;7:155-161.

4. Frank E, Segura C. Health practices of Canadian physicians. Can Fam Physician. 2009;55(8):810-811.

5. Taylor C, Graham J, Potts H, et al. Impact of hospital consultants' poor mental health on patient care. British J Psychiatry. 2007;190:268-269.

6. Wiskar K. Physician health: A review of lifestyle behaviors and preventive health care among physicians. BCMJ. 2012;54(8):419-423.

7. Halbesleben JR, Rathert C. Linking physician burnout and patient outcomes:exploring the dyadic relationship between physicians and patients. Health Care Manage Rev. 2008;33(1):29-39.

8. Frank E. Physician health and patient care. JAMA. 2004;291(5):637.

9. Tyssen R. Health problems and the use of health services among physicians: a review article with particular emphasis on Norwegian studies. Ind Health. 2007;45(5):599-610.

10. Toyry S, Rasanen K, Kujala S, et al. Self-reported health, illness, and self-care among Finnish physicians: a national survey. Arch Fam Med. 2000;9(10):1079-1085.

11. Center C, Davis M, Detre T, et al. Confronting depression and suicide in physicians: a consensus statement. JAMA. 2003;289(23):3161-3166.

12. Gramstad TO, Gjestad R, Haver B. Personality traits predict job stress, depression and anxiety among junior physicians. BMC Medical Education. 2013;13:150.

13. Dresner Y, Frank E, Baevsky T, et al. Screening practices of Israeli doctors' and their patients. Prev Med. 2010;50(5-6):300-303.
14. Fronteira I, Biscaia A. The health status of Portuguese health care professionals. Cah Sociol Demogr Med. 2007;47(3):361-375.

15. Abdulghani HM, Irshad M, Al Zunitan MA, et al. Prevalence of stress in junior doctors during their internship training: a cross-sectional study of three Saudi medical colleges' hospitals. Neuropsychiatr Dis Treat. 2014;10:1879-1886.

16. Rubin R. Recent suicides highlight need to address depression in medical students and Residents. JAMA. 2014;312(17):1725-1727.

17. Petersen MR, Burnett CA. The suicide mortality of working physicians and dentists. Occup Med. 2008;58(1):25-29.

18. Rugulies R. Depression as a predictor for coronary heart disease. a review and meta-analysis. Am J Prev Med. 2002;23(1):51-61.

19. Lichtenstein AH, Appel LJ, Brands M, et al. Diet and lifestyle recommendations revision 2006:A scientific statement from the American Heart Association Nutrition Committee. Circulation. 2006;114(1):82-96.

20. Kouvonen A, Kivimaki M, Cox SJ, et al. Relationship between work stress and body mass index among 45, 810 female and male employees. Psychosom Med. 2005;67(4):577-583.

21. Faghri P, Mignano C. Overweight and obesity in high stress workplaces. J Nutr Disorders Ther. 2013;3(3):e110.

22. Lemaire JB, Wallace JE, Dinsmore K, et al. Food for thought:An exploratory study of how physicians experience poor workplace nutrition. Nutr J. 2011;10(1):18.

23. Ozcelik ON. A research on nutritional habits of the health personnel. Glda. 2000;25(2):93-99.

24. World Health Organization (WHO). Global strategy on diet, physical activity and health. Geneva: World Health Organization; 2004.

25. Knoops KT, de Groot LC, Kromhout D, et al. Mediterranean diet, lifestyle factors, and 10-year mortality in elderly European men and women:the HALE project. JAMA. 2004;292(12):1433-1439.

26. Rashid MN, Fuentes F, Touchon RC, et al. Obesity and the risk for cardiovascular disease. Prev Cardiol. 2003;6(1):42-47.

27. Martin-Timon I, Sevillano-Collantes C, Segura-Galindo A, et al. Type 2 diabetes and cardiovascular disease:Have all risk factors the same strength? World J Diabetes. 2014;5(4):444-470.

28. World Health Organization. Diet, nutrition and the prevention of chronic diseases: report of a joint WHO/FAO expert consultation. Geneva: WHO technical report series; 2002.

29. Poirier P, Eckel RH. Obesity and cardiovascular disease. Curr Atheroscler Rep. 2002;4(6):448-453.

30. American Medical Association. Executive summary of the third report of the National Cholesterol Education Program (NCEP) Adult Treatment Panel III Expert panel on detection, evaluation, and treatment of high blood cholesterol in adults. JAMA. 2001;285(19):2486-2497.

31. Appel LJ, Moore TJ, Obarzanek E, et al. A clinical trial of the effects of dietary patterns on blood pressure. DASH Collaborative Research Group. N Engl J Med. 1997;336(16):1117-1124.

32. Appel LJ, Sacks FM, Carey VJ, et al. The effects of protein, monounsaturated fat, and carbohydrate intake on blood pressure and serum lipids:results of the OmniHeart randomized trial. JAMA. 2005;294(19):2455-2464.

33. Healy GN, Lawler SP, Thorp A, et al. Reducing prolonged sitting in the workplace (An evidence review:full report), Victorian Health Promotion Foundation, Melbourne, Australia. 2012;978-1-921822-24-7.

34. Halim I, Omar AR. A review on health effects associated with prolonged standing in the industrial workplaces. IJRRAS. 2011;8(1):14-21. 
35. Touger-Decker R, van Loveren C. Sugars and dental caries. Am J Clin Nutr. 2003;78(4):881S-892S.

36. Ros E. Health benefits of nut consumption. Nutrients. 2010;2(7):652682.

37. World Cancer Research Fund/American Institute for Cancer Research. Food, Nutrition, Physical Activity, and the Prevention of Cancer: a Global Perspective. Washington DC, USA: American Institute for Cancer Research. 2007.
38. Katie Wiskar. Physician health:A review of lifestyle behaviors and preventive health care among physicians. BCMJ. 2012;54(8):419-423. 